\title{
PROBLEM SOLVING BRIEF THERAPY: A CASE CONDUCTED BY JOHN WEAKLAND
}

\author{
Eduard Carratalà ${ }^{1}$, Anna Vilaregut ${ }^{1}$, Karin Schlanger $^{2}, \&$ \\ Cristina Günther ${ }^{1}$
}

${ }^{1}$ FPCEE Blanquerna, Universitat Ramon Llull, Barcelona, Spain.

${ }^{2}$ Mental Research Institute, Brief Therapy Center, Palo Alto, CA., USA

How to reference this article:

Carratalà, E., Vilaregut, A., Schlanger, K., \& Günther C. (2016). Problem Solving Brief Therapy: A Case Conducted by John Weakland. Revista de Psicoterapia, 27(104), 217-232

\begin{abstract}
This study aimed to analyze a case conducted by John Weakland, as a cofounder of Problem Solving Brief Therapy (PSBT), in order to have a better understanding of the model and how it is developed. Existing literature was reviewed emphasizing the most characteristic aspects of PSBT, which focuses primarily on promoting changes. The case studied is of a couple that requested therapy at the Mental Research Institute (MRI) in 1992 because they were afraid of their son diagnosed with schizophrenic disorder. The couple was visited by John Weakland, cofounder of the PSBT, and considered to be a pioneer in the field of family therapy. With over 30 years of experience as a psychotherapist, he always sought to promote simple strategies for solving problems of human behavior. The case occurred in two sessions, presenting apositive follow-upfeedbackfrom the clients, three weeks after the last session of the therapy. Transcriptions were content analyzed with the support of the Atlas.ti software, considering the therapist's speech turns as units of analysis $(n=136)$. The analysis shows that Weakland, within two sessions, Explores in $52.2 \%$ and Intervenes in $44.1 \%$. Data suggests that PSBT, as applied by Weakland, is characterized for being highly intervening and focused on the present, using a language that facilitates understanding of the process, and thus allows a concise therapy.

Keywords: Systemic Family Therapy, Problem Solving Brief Therapy, Weakland, Problem Definition, Attempted Solutions
\end{abstract}

\begin{abstract}
Resumen
Este estudio tuvo como objetivo analizar un caso llevado por John Weakland, como cofundador del modelo de Terapia Breve de Resolución de Problemas (TBRP), para poder llegar a una mejor comprensión del modelo $y$ de su desarrollo. Se revisó la literatura existente, poniendo énfasis en los aspectos más característicos de la TBRP, que se centra principalmente en la generación de cambios. El caso estudiado es el de una pareja que consultó en el Mental Research Institute (MRI) en 1992 porque tenían miedo de su hijo diagnosticado con trastorno esquizofrénico. La pareja fue visitada por John Weakland, cofundador de la TBRP y considerado pionero en el campo de la terapia familiar. Con más de 30 años de experiencia como psicoterapeuta, siempre buscaba estrategias simples para resolver problemas de la conducta humana. El caso transcurrió en dos sesiones, presentando un feedback positivo en el seguimiento con los clientes, tres semanas después de la última sesión de la terapia. Se analizaron las transcripciones mediante un análisis del contenido, con el soporte del programa informático Atlas.ti, tomando los turnos de habla del terapeuta $(n=136)$ para el análisis. El análisis muestra que Weakland, en dos sesiones, Explora en un $52.2 \%$ e Interviene en un $44.1 \%$. Los datos sugieren que la TBRP, aplicadapor Weakland, se caracteriza por ser altamente interventiva y centrada en el presente, usando un lenguaje que facilita la comprensión del proceso, permitiendo así una terapia concisa.

Palabras clave: Terapia Familiar Sistémica, Terapia Breve de Resolución de Problemas, Weakland, Definición del Problema, Soluciones Intentadas
\end{abstract}

Received: March 3, 2016. Accepted v1: May 17, 2016. Accepted v2: May 19, 2016

Correspondence:

E-mail: EduardCR@blanquerna.url.edu

Postal address: Eduard Carratalà, FPCEE Blanquerna, Císter 24-34, 08022 Barcelona, Spain

(C) 2015 Revista de Psicoterapia 
The therapeutic context is in itself a complex system in which multiple factors are involved in, affecting and conditioning the course and evolution of the process, both positively and negatively (Bateson, 1972; Linares, 2012; Watzlawick, Weakland, \& Fisch, 1974).

A study of a complex system requires recognition of patterns that must be considered as slashes of a larger whole. Maps have been developed, for that purpose, to allow an understanding by slashes and metaslashes (Bateson, 1972), thus approaching a description of the causalities that affect the psychotherapeutic process. In addition, Bateson (1972) stated that "in principle, then, a causal circuit will generate a non-random response to a random event at that position in the circuit at which the random event occurred" (p.410). The understanding of the psychotherapeutic process as a circuit, and events and occurrences that happen, in or out of the context, as different slashes and metaslashes is potentially important.

A systemic research approach must consider the process, the practices, the outcomes, and other variables that might affect the good or poor outcome of psychotherapy (Sexton, \& Datchi, 2014). The results of a therapy do not depend solely on the intervention strategies that are developed therein (Lebow, 2012). In the words of Rohrbaugh (2014), "the systemic paradigm is about understanding human problems and change in a framework of circularity, context, and pattern interruption" (p.435).

There are multiple and diverse trends in psychotherapy, and multiple and diverse models within each of them. After the research developed by Smith, Glass, \& Miller (1980), it is known that a specific therapeutic model is not the most important factor that can predict success or failure of a therapy; it is much more important to look into the details of the specific style that the therapist develops and to look into how the therapeutic relationship unfolds (Friedlander, Escudero, \& Heatherington, 2006). In a more recent study, Botella, Maestra, Feixas, Corbella, \& Valls (2015) highlight that, in a review of multiple studies that study change in psychotherapy, more than $25 \%$ of the times, change occurs due to factors that are common across different psychotherapeutic models. Therefore, developing studies about how an individual therapeutic style is developed is considered a very important factor in the process and success of a psychotherapeutic approach (Blow, Sprenkle, \& Davis, 2007; Corbella, \& Botella, 2004); the therapeutic style should then be taken into account as one of the main elements in the complex map of what happens during the therapy while studying a specific psychotherapeutic model (Escudero, Friedlander, Varela, \& Abascal, 2008; Feixas \& Miró, 1993; Mateu, Vilaregut, Campo, Artigas, \& Escudero, 2014).

Traditionally, Systemic Family Therapy is considered to be a merging of different schools that, despite being sustained by a rich epistemology, are not always homogeneous, due to the independent origins of some basic concepts. One of the main sources that nurtured systemic epistemology was the communicational approach (Watzlawick, Beavin, \& Jackson, 1967) developed in collaboration with 
the Bateson Research Project, with John Weakland as one of the first and most important members. The communicational approach is of special interest for the systemic epistemology as it is considered one of the fundamental influences towards the consolidation of systemic family therapy in the 1960s (Linares, 2012; Ludewig, 2005).

\section{Problem Solving Brief Therapy}

As the Bateson Research Project came to an end, the Mental Research Institute (MRI, 1959) was founded as a therapy and research center. The Institute, already from its beginning, was distinguished because therapy sessions were recorded and a one-way mirror divided a team of therapists dedicated to the session that was taking place. The goal of the recordings was to allow studying the sessions as well as offering the best possible solutions for the clients that were consulting (Linares, 2012; Watzlawick etal., 1967; Watzlawick et al., 1974; Weakland,Fisch, Watzlawick, \& Bodin, 1974).

The MRI provided the cradle for the Problem Solving Brief Therapy (PSBT) model, defined and developed by the first members of the team, Weakland, Fisch, Watzlawick, \& Bodin (1974). PSBT was born intending to offer more effective therapies than those that were available at the time, including the context for a more comprehensive vision. The focus on the families allowed for a relational systemic approach. The team intended to make more agile therapies by limiting the encounters to a maximum of 10 sessions (Weakland et al., 1974).

One of the key elements in the work of Weakland et al. (1974) was to focus on the symptom. The symptom is what the clients are ready to work on because it is what they state when they ask for help. In case of improvement, the symptom serves as a clear sign of the progress. In order to develop the therapeutic work, the problem is understood as a situational and relational event, the intervention being focused on the problem definition that the client brings, and on the attempted solutions that were implemented, understanding these as the loop of positive feedback from the environment that, intending to solve or extinguish the problem, maintain it through homeostatic mechanisms (Schlanger, Cinella, Díaz, \& González, 2014; Waztlawick et al., 1974). The founders proposed PSBT as a fundamentally pragmatic therapeutic approach, conceptualizing and intervening through the direct observation of the interactions of human systems.

Through PSBT, therapists strive to define and focalize the interactional problem, take into account the position of the clients concerning their problem, inquire and synthesize the behaviors of their attempted solutions and use their position to convince them to do the opposite of the basic impulse of their attempted solutions. The essence of the efficacy of this therapy model lies in helping the clients to define their problem in ways that can be solved more efficiently and in the least intrusive possible way (Schlanger et al., 2014; Weakland et al., 1974; Weakland, \& Ray, 1995). 
Considering the effectiveness of PSBT, the research developed by Weakland et al. (1974) showed a success rate of $72 \%$; approximately twenty years later, Rohrbaugh, Shoham, \& Schlanger (1992) and Shoham, Rohrbaugh, \& Patterson (1995) reviewed the team's archives and developed a research that proved that the model had a success rate of $68 \%$, including success and partial success outcomes. Although some research has been developed, Rohrbaugh \& Shoham (2001) reviewed previous studies and confirmed there is still a research gap that needs to be considered and more factors need to be considered in order to learn more of the PSBT model.

\section{The definition of a therapeutic model}

As described by Watzlawick et al. (1967) and Weakland \& Fisch (1992), the focus inherent throughout the therapeutic process is upon understanding the interpersonal relationships, and the problems inherent within them, as a sequence of occurrences, especially referring to the clients' attempted solutions. The sequences are understood in a circular sense, considering that there must be a beginning and an end, thus closing the relational circuit that the clients are enduring. This relational circuit must be interrupted in order to produce a different outcome.

The principles and techniques of PSBT are nurtured from two basic assumptions. First, it is improbable that a specific origin of a problem can be determined, and an attempt for doing so deflects the therapy into a past and historic framework. Therefore, therapy is attended only when there are current behaviors from the clients and their environment, which are maintaining and reinforcing the problem. Second, if the loop of attempted solutions is properly interrupted, the problem will resolve, no matter its nature, origin or extension in time (Weakland et al., 1974).

The therapeutic process is initiated by developing a precise problem definition and then exploring the attempted solutions implemented by the clients and their environment. The intervention is therefore based on developing clear, specific and reachable goals, by defining a plan to produce changes and implementing it in agreement with the clients (Fisch, Weakland, \& Segal, 1982; Watzlawick et al., 1974; Weakland, \& Fisch, 1992; Weakland et al., 1974).

In order to do therapy briefly, the formula that the Palo Alto group followed is, as Rohrbaugh \& Shoham (2001) describe:

(a) define the complaint in specific behavioral terms; (b) set minimum goals for change; (c) investigate solutions to the complaint; (d) formulate ironic problem-solution loops (how 'more of the same' solutions leads to more of the complaint, etc); (e) specify what 'less of the same' will look like; (f) understand clients' preferred views of themselves, the problem, and each other; (g) use client position to interdict problem-maintaining solutions; and (h) nurture and solidify incipient change. (p.72)

Strategies and techniques characteristic of the PSBT model focus on the interruption of the attempted solutions that maintain the problem, rather than on the 
problem itself(Bermúdez, \& Brick, 2010; Fisch, Ray, \& Schlanger, 2009; Rohrbaugh, $\&$ Shoham, 2001; Schlanger et al., 2014). These strategies and techniques are shown in Table 1, with a brief definition for each concept, pointing out the importance of relational and familiar elements in PSBT.

Table 1.

Strategies and techniques of PSBT model (adapted from Bermúdez, \& Brick, 2010)

\begin{tabular}{ll}
\hline Strategies and Techniques & \multicolumn{1}{c}{ Description } \\
\hline Determine the goals & Establish criteria to evaluate expected changes. \\
Choose the minimal change & $\begin{array}{l}\text { Choice of a new behavior in agreement with the family to } \\
\text { begin the expected changes. }\end{array}$
\end{tabular}

Doing the opposite of what was Recommend behaviors that contradict those that maintain being done the problem.

Speak the language of the client Adopt and understand the clients' idiosyncrasy, and their attitude towards the difficulty they are presenting, allowing for a better acceptance of what the therapist suggests.

Avoid confrontation

Take an equal and non-superior position with the family.

Problem definition from an

Avoid problem definitions that point to individual interactional pattern pathology, to promote a circular understanding of the problem.

Clarification of the attempted solutions

Help the family realize that the attempted solutions have not worked.

Reframing

Offer new meanings to the descriptions that the families bring, both regarding problem definition and change.

Prescription of homework

Ask the family to do tasks in-between sessions, promoting a continuity of the in-session work.

In order to have a deeper understanding of the PSBT model, the content analysis of a therapy conducted by John Weakland (as a cofounder of the model) was performed to look in the details as how the therapist's style was developed. Learning about this presents a more complex knowledge of how the PSBT unfolds, since the model has been studied in terms of effectiveness, and still requires more research in order to fill in the gaps of what it is that actually occurs in its therapies, as it is brought out in the literature.

\section{Methodology}

\section{Single-Case Study}

The entire analysis followed a single-case design (Barlow, \& Hersen, 1984; Yin, 1989) through indirect semi structured observation. This protects the reliability of the results, considering the potential and the limitation of this design 
simultaneously. Therefore, it is understood that the results and conclusions to be extracted should match with the analyzed case, while allowing reaching a deeper understanding of the content. Consequently, this study was developed through a content analysis of the transcriptions, considering only contributions of the therapist in two psychotherapy sessions. This type of analysis refers to a set of methods and procedures that emphasize in the text and establish two degrees of complexity, descriptive and inferential, taking into account both qualitative and quantitative analysis techniques (Stake, 2010).

\section{Participants}

The clients. In order to respect confidentiality, names and other identifying details of the clients have been disguised. Also, a consent form was signed by the clients, allowing using this material for research or teaching purposes.

The clients were a married couple that attended the MRI in 1992, Arthur, 73 year old, and Rose, 61 . They had three sons: Dick, 29, Jason, 27, and Jake, 26. Arthur had one more son from a previous relationship, Patrick, 40 year old, who practiced as a therapist in a different town.

The couple sought consultation because of Jason, who had been diagnosed with a Schizophrenic Disorder. They started having issues with Jason approximately 6 years before coming to the MRI. They were referred by Patrick, in search of a different kind of therapy. During those years they tried to get help from different institutions, but all of them required Jason to attend and participate personally, which he did not accept. When the parents came to know that they could be helped at the MRI without needing Jason to be present, they decided to ask for an appointment seeking the help; they complained about serious difficulties in managing Jason's behavior and attitude, fearing for their own physical safety, and that of the rest of the family.

Arthur and Rose found themselves in a critical situation, beyond the complexity of the case, because they feared their son and what he might be capable of doing. The main - and simplified - presenting problem the couple complained was that they were afraid. This fear was motivated by the destructive behaviors of Jason towards them and their inability to modify the repetitive situations.

The therapist. John Weakland (1919-1995), at the time was 73 years old and was considered to be a pioneer in the field of family therapy. In his obituary (Thomas, 1995), Weakland was defined as "an innovative psychotherapist who helped originate the field of family therapy and created elegantly simple strategies for solving problems of human behavior" (p. 1). He had an experience of over 30 years in the field of psychotherapy, being one of the first members of the Bateson Research Project as well as part of the first team of the MRI.

Weakland, entering Cornell University by the age of 16, started out as a chemical engineer but soon became interested in anthropology next to Gregory Bateson and Margaret Mead at the New School in New York (Thomas, 1995). His 
first publication in the field of family therapy was the very influential paper "Towards a theory of Schizophrenia" (Bateson, Jackson, Haley, \& Weakland, 1956) (Cade, 1995). After that, he participated in over 60 research papers and authored six books in the field of family therapy (Thomas, 1995).

Following with the MRI protocol, a follow-up evaluation was assessed three weeks after the therapy was concluded. The couple considered the therapy useful and identified that their main problem was resolved. The follow-up was assessed as +1 , meaning that change was achieved and the clients were sufficiently satisfied with the therapy they received.

\section{Material}

Transcriptions were analyzed for a therapy conducted by Weakland with the PSBT model. The case was framed in two sessions of approximately one hour each. The therapy was documented with the support of audiovisual recordings for both sessions.

\section{Procedure}

Firstly, various cases were looked upon, and one was selected based on its specific characteristics: (1) The therapy was conducted by a cofounder of the PSBT model; (2) The quality of the recordings was sufficient to allow access to the entire case; (3) It followed the MRI's protocol; (4) The subjective follow-up evaluation was positive $(+1$ or +2$)$.

Secondly, the two sessions of the selected case were transcribed literally. The resulting transcriptions were reviewed by a team of professionals, experts in the systemic model, to achieve consensus regarding the accuracy of the text.

In third step, a repeated reading of the transcriptions was carried out to identify fragments of the text that were relevant to the purpose of the study. The fragments where Weakland contributed were selected. It is important to clarify that the interventions were considered in the original context in the purview of the therapeutic conversation and therefore the client's contributions, though not categorized themselves, were always used to contextualize the analysis of the selected fragments.

In fourth step, speech turns were selected as units of analysis (UAs) based on the divisions defined in the transcriptions. It resulted in a total of N=604 UAs, corresponding to $n=136$ UAs of contributions from Weakland; all of them were considered in the analysis, carried out by using Atlas.ti (v.5.0) software.

In fifth step, in order to systematize the process, analysis categories were defined based on the existing literature and the support of the MRI team. A total of twenty categories were defined, which, during the analysis, were mapped on the basis of how they were related to each other. A total of 4 category grouping levels were achieved, with saturation in the third and fourth level categories - a total of 13 saturated categories. The definition of each saturated category respected what is 
defined in the model, adapting the meaning and the definition through the analysis developed. Due to the meaning of the categories and the nature of the UAs defined - speech turns - co-occurrence of categories happens in many of the UAs (i.e. one single speech turn might be simultaneously categorized as Prescribing homework and Choosing the minimal change).

In order to assess interferences of an individual researcher, a group of auditors made a consensus to supervise the procedure. A team of four systemic-oriented psychologists was assigned for the analysis and discussion of the results. The team had an experience of 5-30 years in the field with an average of 14 years. Following the Single Case Design Standards (Kratochwill et. al., 2013), the researchers determined by a consensus when and how UAs were categorized. Among the 13 saturated categories, the research team agreed in $92 \%$ of the categorization. On the $8 \%$ of disagreement, consensus was achieved by clarifying the meaning of the existing categories or by creating new more specific categories when required. As seen in Figure 1 in the results, when categorizing how Weakland explores The problem definition, the analysis required to create the two new sub-categories In an open manner and Directing towards the present.

\section{Results}

\section{Categorical qualitative analysis}

When analyzing Weakland's speech turns, we observed that he Explores both The problem definition and The attempted solutions. The category Explores refers to those contributions of the therapist focused on inquiring about what moves the client to ask for therapy and inquire about the relational description that the client offers. It is observed, looking into The problem definition, that he does so In an open manner as well as Directing towards the present.

When we considered Intervenes, we understood this category as those contributions of Weakland where he promoted change to occur. We observed, while classifying, that his interventions have two cores of the intervention. On the one hand On the problem definition and on the other On the attempted solutions. When intervening On the problem definition, he does so by Defining the problem from an interactional pattern and Reframing the problem definition. When intervening On the attempted solutions, he does so by Clarifying the attempted solutions, Determining the goals, Choosing the minimal change, Doing the opposite of what was being done, Reframing change and Prescribing homework.

Weakland Maintains a therapeutic attitude, understood as those contributions from the therapist aiding on the client's comfort and aiming to ease the process for them, by Speaking the client's language and Avoiding conflict with the family.

All of these results are presented in a conceptual map in Figure 1, unveiling the frequencies in which Weakland develops the processes, defined in these categories that allow a better understanding of the categorical analysis developed. 
In order to assist the procedure and analysis, the reframing technique was divided into the categories Reframing the problem definition and Reframing change, which allowed to distinguish whether the therapist's action intervened on the problem definition or the attempted solutions, respectively (see Figure 1). All categories merge into the category Weakland, which is understood as the full set of styles, interventions and explorations that define the praxis of Weakland as a therapist. The category Explores refers to Weakland's contributions to search for information about the presenting case, either inquiring into The problem definition or The attempted solutions. The exploration of the problem definition was divided in two smaller categories, In an open manner, which refers to problem definition exploration in general terms, and Directing towards the present, which encloses the guided exploration intended to direct the clients' discourse specifically to the present. The category Intervenes encompasses the contributions focused on promoting changes in the behavior or discourse of the clients. Intervention was done either On the problem definition or On the attempted solutions, each of them grouping their own more specific categories (see Figure 1). Lastly, the category Maintains a therapeutic attitude encompasses contributions that focus on easing the therapeutic process for the clients, adapting to their needs and promoting a better relationship between the therapist and the clients.

Most categories achieve saturation at the fourth level of analysis except for the following three, which saturate at the third level: (1) The attempted solutions; (2) Speaking the client's language; (3) Avoiding conflicts with the family (see Figure 1).

Representative examples from the literal transcriptions are shown in Table 2, which illustrate each category that achieves saturation, and help in the understanding of what they meant in the present analysis. 


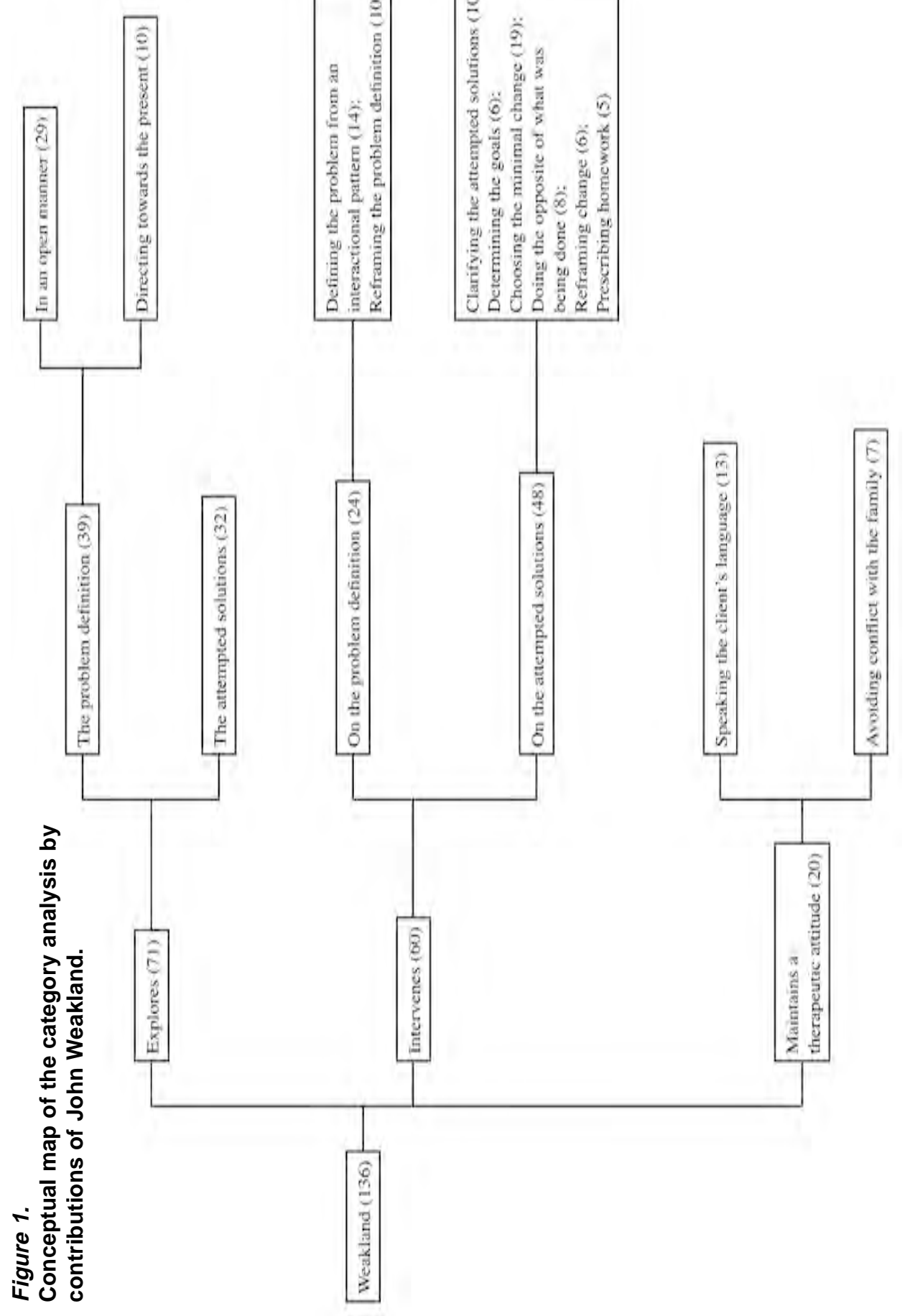


Table 2

Selection of representative examples of the categories achieving saturation.

\begin{tabular}{|c|c|}
\hline Category & Example \\
\hline In an open manner & "Tell me a little more about what, just what you see going on." \\
\hline $\begin{array}{l}\text { Directing towards the } \\
\text { present }\end{array}$ & $\begin{array}{l}\text { "I think it would help if you could now tell me what's going on right now } \\
\text { and then we can fill in as much as necessary." }\end{array}$ \\
\hline $\begin{array}{l}\text { The attempted } \\
\text { solutions }\end{array}$ & "But what do you say if he says 'you are the devil'?" \\
\hline $\begin{array}{l}\text { Defining the problem } \\
\text { from an interactional } \\
\text { pattern }\end{array}$ & $\begin{array}{l}\text { "[...] it sort of looks like he might be feeling that the other members of the } \\
\text { family are included, and he's sort of the hard man out, and he's gotten } \\
\text { very resentful with that?" }\end{array}$ \\
\hline $\begin{array}{l}\text { Reframing the problem } \\
\text { definition }\end{array}$ & $\begin{array}{l}\text { "[...] these situations that are unusual, but that, that sort of thing l've } \\
\text { heard of people being destructive before, but l've never really heard of... } \\
\text { he's destructive and then he patches it up." }\end{array}$ \\
\hline $\begin{array}{l}\text { Clarifying the } \\
\text { attempted solutions }\end{array}$ & $\begin{array}{l}\text { "I don't know, but I could even think that in the rather distorted way he } \\
\text { seems to be thinking he could even take your offers of help and concern } \\
\text { as a perfect put down." }\end{array}$ \\
\hline
\end{tabular}

Determining the goals "[...] if he says a warm 'good morning mom how are you?' well, I certainly would take that as a positive sign, and I like your answer in terms of it's concrete and observable [...]"

Choosing the minimal "[...] suppose he did something that he has never done, like come in and change apologize for some piece of destructive behavior, would that be different enough?"

Doing the opposite of "The main thought is, what would be so different, so uncharacteristic of what was being done what he's come to expect from you, that it would make his jaw drop."

Reframing change "Well, but I think... I don't really mean this to as fastidious as it's gonna sound but at least in that example you were sort of 50-50."

Prescribing homework "So step by step, so think small, and think concrete, what would something observable be if you could saw it you could say to yourselves, I'm not out of the woods, but that's a possible thing", and I know you're coming a long way, so timing of things is partly up to you, I would like to be feasible to meet with you again at this time next week."

Speaking the client's "If we could only reverse that reversal... than we would be in to language something."

Avoiding conflict with "So they sort of put the weight on me, but you do have a point, they the family conceivably could be overly cautious and the ultimate test would be up to you, and not up to them."

\section{Category percentage analysis}

In order to have a deeper understanding of the PSBT model, it is necessary to take into account the percentages of each category, out of the total of analysis units in which Weakland speaks $(n=136)$. Table 3 shows that $52.2 \%$ of the UAs refer to 
the exploration, $44.1 \%$ to the intervention, and $14.7 \%$ corresponds to Maintains a therapeutic attitude. $17.6 \%$ of the UAs are categorized as On the problem definition, while $35.3 \%$ correspond to On the attempted solutions. The highest percentage of those categories grouped in the intervention On the attempted solutions refer to Choosing the minimal change, with 14\%. The categories encompassed in Maintains a therapeutic attitude are distributed in $9.6 \%$ for Speaking the client's language and $6.1 \%$ for Avoiding conflict with the family.

\section{Table 3.}

Percentages of each category out of the totality of the UAs.

\begin{tabular}{lrrr}
\hline Category & & Frequency & \multicolumn{1}{c}{$\%$} \\
\hline Explores & & 71 & 52.2 \\
& The problem definition & 39 & 28.7 \\
& In an open manner & 29 & 21.3 \\
Directing towards the present & 10 & 7.3 \\
The attempted solutions & 32 & 23.5 \\
\hline Intervenes & 60 & 44.1 \\
On the problem definition & 24 & 17.6 \\
& Defining the problem from an interactional pattern & 14 & 10.3 \\
$\quad$ Reframing the problem definition & 10 & 7.3 \\
& On the attempted solutions & 48 & 35.3 \\
$\quad$ Clarifying the attempted solutions & 10 & 7.3 \\
Determining the goals & 6 & 4.4 \\
$\quad$ Choosing the minimal change & 19 & 14.0 \\
Doing the opposite of what was being done & 8 & 5.6 \\
Reframing change & 6 & 4.4 \\
$\quad$ Prescribing homework & 5 & 3.7 \\
\hline Maintains a therapeutic attitude & 20 & 14.7 \\
Speaking the client's language & 13 & 9.6 \\
Avoiding conflict with the family & 7 & 6.1 \\
\hline
\end{tabular}

Similarly, in Table 4, percentages are shown for each of the third and fourth level categories allowing a comparison between the first and second sessions. There is a greater percentage of contributions in the first session, wherein Weakland Explores, presenting 51.3\% on The problem definition and $62.5 \%$ on The attempted solutions, whereas in the second session there is a greater percentage of contributions, wherein Weakland Intervenes, showing $75 \%$ and $66.7 \%$ on On the problem definition and On the attempted solutions respectively. Three categories stand out by $100 \%$ occurrence in the second session: Determining the goals, Doing the opposite of what was being done and Avoiding conflict with the family. 
Table 4.

Presence percentage of third and fourth level categories within each session.

\begin{tabular}{lrr}
\hline Category & Session 1\% & Session 2 \% \\
\hline Explores & & \\
The problem definition & 51.3 & 48.7 \\
In an open manner & 48.3 & 51.7 \\
$\quad$ Directing towards the present & 60.0 & 40.0 \\
The attempted solutions & 62.5 & 37.5 \\
\hline Intervenes & & \\
On the problem definition & 25.0 & 75.0 \\
Defining the problem from an interactional pattern & 14.3 & 85.7 \\
$\quad$ Reframing the problem definition & 40.0 & 60.0 \\
On the attempted solutions & 33.3 & 66.7 \\
Clarifying the attempted solutions & 50.0 & 50.0 \\
Determining the goals & 0.0 & 100.0 \\
Choosing the minimal change & 31.6 & 60.4 \\
Doing the opposite of what was being done & 0.0 & 100.0 \\
Reframing change & 66.7 & 33.3 \\
$\quad$ Prescribing homework & 80.0 & 20.0 \\
\hline Speaking the client's language & & \\
Avoiding conflict with the family & 53.8 & 46.2 \\
\hline
\end{tabular}

\section{Discussion}

The analysis of Weakland's contributions within the therapeutic conversation in this case study allows a better understanding about the application of the theoretical model described by Weakland et al. (1974).

The way Weakland develops the exploration clarifies that the PSBT model intends to look for what brings clients to therapy, always defining it in terms of the present time. When clients focus on the occurrences or behaviors from the past, Weakland redirects their discourse to understand what is maintained in the present of what initiated in the past. Considering the category Explores, there is 52.2\% of the total of Weakland's contributions, which focus on understanding what brings the clients to therapy and how they get there; it emphasizes the fact that what is most important is that which is maintained, both for the problem definition and for the attempted solutions. The theory of the model is presented in this analysis; it underlines the importance of what is occurring and maintained in the present, even though the problem started in the past. Therefore, we spotlight how Weakland (1976), consistent with his own writing, is attempting to work and intervene on the behaviors in the present, without chasing after the stored memories and centering the intervention on past behaviors, which hinders a brief and efficient work.

The fact, $44.1 \%$ of the UAs are directed towards the intervention, and hence to promote changes, demonstrates that PSBT is a highly intervening model, as described in the work of Weakland and Fisch (1992) and Weakland et al. (1974), 
given that this percentage is given in a two-session therapy. When considering the qualitative meaning of the categories grouped in Intervenes and the interventions they refer to, we see that they are equally important, even if they are presented in different percentages due to the content of the interventions and the way they are presented. It is within the general discourse of the therapist to promote a problem definition from an interactional pattern, as it is first described by Weakland et al. (1974) and most recently by Schlanger et al. (2014), only if the clients are able to see the role they play in the problem maintenance, then only they will be able to act differently and develop new solutions, thus breaking the positive feedback loop that maintains and reinforces the problematic behavior they complained about.

We emphasize the importance, as Fisch et al. (1982) and Weakland et al. (1974) do, of the category Choosing the minimal change which, although present in $14 \%$ of all the UAs, allows Weakland to determine the goals in a more precise and clear way, given that, in agreement with the clients, the therapist works to find the behavior that would allow the family to know that change has begun, and that the problem has started to resolve.

The category Prescribing homework only appears in 3.7\% of the UAs; however, it is contrary to what we expect based on the work of Weakland et al. (1974). The great importance of this category is brought out in the qualitative analysis that appears always at the end of each session. The way in which the tasks are prescribed is centered in the integration of the accumulated information, and the interventions done during the session, in order to help the clients maintain a behavior that interrupts the blockage of the attempted solutions until the next session.

The similar percentage distribution of the therapeutic attitude in the both sessions points out the importance of an attitude that facilitates communication, essential according to Weakland et al. (1974). It stands out in the analysis that the use of the clients' language was necessary in order to assist them in the understanding of the therapeutic process. Similarly, the use of an idiosyncratic language with the clients stands out in the whole process, given that Weakland maintains it across the therapy, both observing and intervening, as per the theory of the model (Weakland et al., 1974).

The $100 \%$ presence of the three categories in the second session (Determining the goals, Doing the opposite of what was being done and Avoiding conflict with the family) becomes more understandable when considering an integration of the quantitative and qualitative values, occurring frequently in parallel, assuring a better result of the interventions. This allows Weakland to maintain a level of empathy and respect with the clients, while attempting interventions that might be otherwise uncomfortable, a principle that stands out in the communicational approach of Watzlawick et al. (1967).

While analyzing Weakland's contributions to the therapeutic conversations, the collaboration between the categories Defining the problem from an interactional 
pattern and Clarifying the attempted solutions is brought out. These categories are mutually braced in how Weakland uses them, reaching for better results in the process of change. Additionally, Reframing the problem definition and Reframing change are complemented in order to mitigate the gravity described by the clients and aid in the recognition of a behavior that would interrupt the problem.

The research presented in this paper intends to work towards filling in the research gaps highlighted in the literature. It is important to point out that the results and conclusions presented in this study are applicable to the analyzed case. Therefore, in order to continue working to develop the research of PSBT, further investigations should be developed, taking into consideration various client pathologies and presenting problems, procuring a rigorous research assessment that considers the most important factors that predict a successful therapy.

\section{Author notes:}

1. Participants from this study signed a consent form allowing for the material to be used for research and teaching purposes. Confidentiality was respected throughout the study.

2. This study was carried out with the funds obtained by the agreement between URL and the Departament d'Economia i Coneixement of the Generalitat de Catalunya.

\section{Bibliographic references}

Barlow, D., \& Hersen, M. (1984). Single-case experimental designs: Strategies for studying behavior change. New York: Pergamon Press.

Bateson, G., Jackson, D., Haley, J., y Weakland, J. (1956). Toward a theory of schizophrenia. Behavioral Science, 1(4), 251-264.

Bateson, G. (1972). Steps to an ecology of mind. Chicago: University of Chicago Press.

Bermúdez, C., \& Brik, E. (2010). Terapia familiar sistémica. Aspectos teóricos y aplicación práctica. Madrid: Síntesis.

Blow, A., Sprenkle, D., \& Davis, S. (2007). Is who delivers the treatment more important than the treatment itself? The role of the therapist in common factors. Journal of Marital and Family Therapy, 33(3), 298-317. doi: $10.1111 / \mathrm{j} .1752-0606.2007 .00029 . \mathrm{x}$

Botella, L., Maestra, J., Feixas, G., Corbella, S., \& Vall, B. (2015). Integración en Psicoterapia 2015: Pasado, Presente y Futuro. Integración en Psicoterapia. doi: 10.13140/RG.2.1.1351.3040

Cade, B. (1995). John H. Weakland (1919-1995): Tribute to a pioneer. Journal of Family Therapy, 19, 357-362.

Corbella, S., \& Botella, L. (2004). Investigación en psicoterapia: proceso, resultado y factores comunes. Barcelona: Visión Net.

Escudero, V., Friedlander, M. L., Varela, N. \& Abascal, A. (2008). Observing the therapeutic alliance in family therapy: associations with participants' perceptions and therapeutic outcomes. Journal of Family Therapy, 30, 194-214. doi: 10.1111/j.1467-6427.2008.00425.x

Feixas, G., \& Miró, M. (1993). Aproximaciones a la psicoterapia: una introducción a los tratamientos psicológicos. Barcelona: Paidós.

Fish, R., Weakland, J., \& Segal, L. (1982). Tactics of change: Doing Therapy Briefly. San Francisco: Jossey-Bass.

Fisch, R., Ray, W., \& Schlanger, K. (2009). Focused problem resolution. Selected papers of the MRI Brief Therapy Center. Phoenix: Zeig, Tucker \& Theisen.

Friedlander, M., Escudero, V., \& Heatherington, L. (2006). Therapeutic Alliances in Couple and Family Therapy: An Empirically Informed Guide to Practice. Washington: American Psychological Association.

Kratochwill, T. R., Hitchcock, J. H., Horner, R. H., Levin, J. R., Odom, S. L., Rindskopf, D. M., \& Shadish, W. R. (2013). Single-Case Intervention Research Design Standards. Remedial and Special Education, 34(1), 26-38. doi: $10.1177 / 0741932512452794$ 
Lebow, J. L. (2012). Common factors, shared themes, and resilience in families and family therapy. Family Process, 51(2), 159-162. doi:10.1111/j.1545-5300.2012.01400.x.

Linares, J. L. (2012). Terapia familiar ultramoderna. La inteligencia terapéutica. Barcelona: Herder.

Ludewig, K. (2005). Einführung in die theoretischen grundlagen der systemischen therapie. Heidelberg: CarlAuer-Systeme Verlag.

Mateu, C., Vilaregut, A., Campo, C., Artigas, L., \& Escudero, V. (2014). Construcción de la Alianza Terapéutica en la terapia de pareja: estudio de un caso con dificultades de manejo terapéutico. Anuario de Psicología, 44(1), 95-115.

Rohrbaug, M. J. (2014). Old wine in new bottles: Decanting systemic family process research in the era of evidencebased practice. Family Process, 53(3), 434-444. doi:10.1111/famp.12079

Rohrbaugh, M. J., \& Shoham, V. (2001). Brief Therapy Based on Interrupting Ironic Processes: The Palo Alto Model. Clinical Psychology, 8(1), 66-81.

Rohrbaugh, M. J., Shoham, V., \& Schlanger, K. (1992). In the brief therapy archives: A progress report. University of Arizona. Unpublished manuscript.

Schlanger, K., Cinella, M., Díaz, G., \& González, P. (2014). Hoy en Palo Alto: un trabajao en escuelas californianas con población inmigrante. In Pensamiento Sistémico. Nuevas perspectivas y contextos de intervención. México: Litteris.

Shoham, V., Rohrbaugh, M. J., \& Patterson, J. (1995). Problem-and solution-focused couple therapies: The MRI and Milwaukee Models. In Clinical handbook of marital therapy. New York: Guilford Press.

Sexton, T., \& Datchi, C. (2014). The development and evolution of family therapy research: Its impact on practice, current status, and future directions. Family Process, 53(3), 415-433. doi:10.1111/famp.12084

Smith, M. L., Glass, G. V., \& Miller, T. (1980). The benefits of psychotherapy. Baltimore: John Hopkins University Press.

Stake, R. E. (2010). Qualitative research: studying how things work. New York: The Guilford Press.

Thomas, R. (1995, July 16). John Weakland, an Originator of Family Therapy, Is Dead at 76. The New York Times. Retrieved from http://www.nytimes.com/1995/07/16/obituaries/john-weakland-an-originator-of-familytherapy-is-dead-at-76.html

Watzlawick, P., Beavin, J., \& Jackson, D. (1967). Pragmatics of human communication. New York: Norton.

Watzlawick, P., Weakland, J., \& Fisch, R. (1974). Change. Principles of problem formation and problem solution. New York: Norton.

Weakland, J., \& Fisch, R. (1992). Brief therapy MRI style. In Focused Problem Resolution. Selected Papers of the MRI Brief Therapy Center. Phoenix: Zeig, Tucker \& Theisen.

Weakland, J., Fisch, R., Watzlawick, P., \& Bodin, A. M. (1974). Brief therapy: Focused problem resolution. Family Process, 13, 141-168.

Weakland, J.(1976). Communication Theory and Clinical Change. In Focused problem resolution. Selected papers of the MRI Brief Therapy Center. Phoenix: Zeig, Tucker \& Theisen.

Weakland, J., \& Ray, W. (1995). Propagations: Thirty years of influence from the Mental Research Institute. New York: Haworth.

Yin, R. K. (1989). Case study research: design and methods. Newbury Park: Sage Publications. 